Case Report

\title{
Bilateral Pulmonary Embolism after a Short-Haul Flight in a Man with Multiple Risk Factors including Sickle Cell Trait
}

\author{
Kamille Abdool, Kanterpersad Ramcharan, Antonio J. Reyes, \\ Nadiene Lutchman, and Adrian Alexander \\ Department of Medicine, San Fernando Teaching Hospital, San Fernando, Trinidad and Tobago \\ Correspondence should be addressed to Kanterpersad Ramcharan; kramcharan79@yahoo.com
}

Received 8 January 2017; Revised 16 March 2017; Accepted 19 March 2017; Published 29 March 2017

Academic Editor: Aristomenis K. Exadaktylos

Copyright (C) 2017 Kamille Abdool et al. This is an open access article distributed under the Creative Commons Attribution License, which permits unrestricted use, distribution, and reproduction in any medium, provided the original work is properly cited.

\begin{abstract}
We report a case of pulmonary embolism (PE) in an Afro-Caribbean man following a short commercial flight of less than 5,000 kilometers $(\mathrm{Km})$ in economy class with a 1-month interval between journeys. He had an elevated body mass index (BMI) and sickle cell trait (SCT) with hyperhomocysteinemia. No other preexisting source of venous thrombosis was found. We posit that venous thromboembolism (VTE) and/or PE may have been a complication of SCT in an individual with other multiple risk factors. We discuss the possible interaction of these risk factors for VTE and/or PE and the implications for travelers at risk. The need for a PE risk score and guidelines for the prophylaxis of thromboembolism among travelers exists.
\end{abstract}

\section{Introduction}

Travel-associated PE with or without detectable deep venous thrombosis (DVT) has been documented in hospitals that are closely located to large bustling airports [1-3]. The data gathered from 3 studies at Frankfurt, Charles de Gaulle, and Madrid-Barajas airports showed a low risk of the economy class syndrome (ECS) which strictly depended on the flight distance. It was found that there was a greater risk with flight distances of greater than $5,000 \mathrm{~km}$ [13].

Multiple risk factors and preexisting comorbidities can add to the risk and prognosis. These include thrombophilia (40\%), recurrent VTE (16\%), Factor V Leiden (13\%), VTE family history (10\%), neoplastic disease (7\%), and other predisposing factors such as pulmonary hypertension, Behcet's disease, use of oral contraceptives, and a BMI greater than $35 \mathrm{~kg} / \mathrm{m}^{2}(10 \%)$ [1].

We report a case of PE in an Afro-Caribbean man following a short commercial flight of less than $5,000 \mathrm{~km}$ in economy class. He had an elevated BMI, SCT, and hyperhomocysteinemia as additional risk factors.

\section{Case Presentation}

A previously well, 39-year-old Afro-Caribbean man with known SCT was admitted to the hospital for worsening shortness of breath and pleuritic chest pain following a commercial flight from Trinidad to Jamaica via Miami. The travel distance of $3,528 \mathrm{Km}$ was covered in a time frame of 5 hours via a break from a connecting flight. The patient had experienced shortness of breath on moderate exertion, with no chest pain or hemoptysis, during the 1-month stay in Jamaica, but he sought medical attention only in Trinidad, one month later after the return flight via the same route.

There was no previous history or clinical evidence of DVT. The blood pressure was $135 / 79 \mathrm{~mm} \mathrm{Hg}$, the pulse was 92 beats per minute, the respiratory rate was 24 respirations per minute, and the oxygen saturation was $85 \%$ on room air which improved to $100 \%$ after increasing gradually the oxygen therapy to $15 \mathrm{~L} / \mathrm{min}$ via face mask. Physical examination findings were insignificant except for a BMI of $34 \mathrm{~kg} / \mathrm{m}^{2}$. Arterial blood gases on oxygen therapy showed a compensated respiratory alkalosis. The patient's Wells score was calculated as 3 which signifies a moderate risk for PE [4]. The D-Dimer test was reported to be greater 


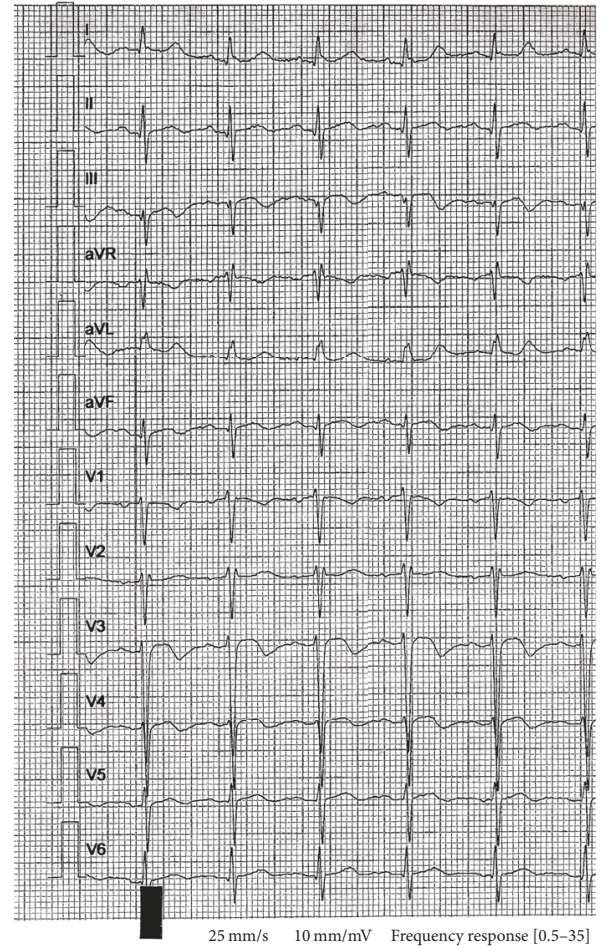

FIGURE 1: Photograph of ECG demonstrating a small Q wave with $\mathrm{S}$ and $\mathrm{T}$ waves that can be seen in lead III, the inferior leads (II, III, and aVF), T wave inversions in the right precordial leads (V1-4), and clockwise rotation-shift of the R/S transition point towards V6 with a persistent $\mathrm{S}$ wave in $\mathrm{V} 6$, all consistent with pulmonary embolism (settings: $25 \mathrm{~mm} / \mathrm{s}$ and $10 \mathrm{~mm} / \mathrm{mV}$ ).

than $10,000 \mu \mathrm{g} / \mathrm{L}$ (normal < 500). An electrocardiogram (ECG) showed changes consistent with PE which reverted to normal on patient's recovery (Figure 1). Computed Tomography Pulmonary Angiogram (CTPA) showed large filling defects in both main pulmonary arteries and bilateral lobar pulmonary arteries with bilateral lower lobe pulmonary atelectasis (Figures 2(a) and 2(b)). Transthoracic echocardiography, chest X-ray, and CT scan of abdomen and pelvic were reported to be normal. Doppler ultrasound of the venous systems of both lower limbs did not show evidence of DVT. Screening for prothrombotic states was negative except for HbAS genotype (HbA: $61.2 \%$ and $\mathrm{HbS}: 36.6 \%$ ) and hyperhomocysteinemia at $32 \mu \mathrm{mol} / \mathrm{L}$ (normal $<16$ ). Investigations for infectious, autoimmune, haematological, respiratory, cardiovascular, and mitotic diseases were negative. Serum vitamin B12 and folic acid levels were normal. Genetic testing for homocysteine polymorphisms and flow cytometry for paroxysmal nocturnal hemoglobinuria were unavailable. Diagnosed with bilateral PE, subcutaneous enoxaparin was started and, on day 2, $15 \mathrm{mg}$ orally twice daily loading dose of rivaroxaban was given. On day 4 , he was discharged for outpatient care. Rivaroxaban $20 \mathrm{mg}$ orally daily was initiated from day 21 and continued for a year. A treadmill stress test using Bruce protocol was negative for coronary artery ischemia six weeks after discharge from hospital. One year later, the patient remains well, is off medications, and has lost 5 kilograms of body weight.

\section{Discussion}

PE or VTE has been reported after long traveling by car, bus, and train. Severe PE is extremely rare after flights of less than 8 hours [1]. VTE or PE events are more prevalent among passengers traveling long distances $(>5,000 \mathrm{Km})$, with sedentary life style, poor mobility, and bended legs in economy class and/or with previous poorly controlled risk factors for thrombosis [1]. This has led to the use of the term ECS. Prophylactic measures for long-haul flights have been advocated in an attempt to minimize this risk but no risk scale has been described to guide physicians.

PE occurs frequently with no demonstrable source of primary venous thrombosis as in our patient. A meta-analysis has shown that the prevalence of DVT in suspected PE is approximately $18 \%$, and in proven $\mathrm{PE} 36-45 \%$. The absence of demonstrable DVT as in our case is well recognized in patients with PE. The Frankfurt study found that only $48 \%$ of patients with PE and ECS had demonstrable venous thrombosis [1].

Interestingly, the mean BMI of these patients was $35 \mathrm{~kg} / \mathrm{m}^{2}$, unveiling a trend to higher values compared with ECS patients with predisposing factors (mean BMI 28; $P=$ 0.364) [1]. The inclusion of the BMI as additional risk factor for PE among air travelers was emphasized because a high $\mathrm{BMI}$ can be a reversible risk for PE. Patients with PE due to non-air-travel ECS were significantly overweight compared with air-travel-associated $\mathrm{PE}$, indicating that obesity might be a crucial risk factor for prolonged car, bus, or train traveling. Nevertheless, in patients with known risk factors for PE or VTE such as thrombophilia, positive history of VTE, or obesity, preventive measures on long-haul flights over $5,000 \mathrm{~km}$ should be encouraged, the authors noted [1].

Our patient had a combination of multiple risk factors for PE or VTE such as obesity, economy class travel, SCT with hyperhomocysteinemia, and African ethnicity. The patient had almost two congenital risk factors (SCT and hyperhomocysteinemia) that are per se sufficient to explain a PE. The patient had also an acquired risk factor such as two separate short-haul flights in the last four weeks. Although one cannot specify which of the congenital or acquired risk factors played a major role in this patient, the existence of multiple risk factors in a single individual traveling by air is enough evidence to support the development of PE. It is thus possible that our patient may have had subclinical calf thrombosis resulting in ECS with PE. We could not demonstrate clinical or ultrasonographic evidence of venous thrombosis as a source of embolism in this case but these observations are not unusual.

Sickle cell disease and venous thrombosis have been widely reported but the consideration of SCT as a risk factor for PE has only recently been gaining attention. SCT occurs in approximately 300 million people worldwide, with the highest prevalence of approximately $30 \%$ to $40 \%$ in sub-Saharan Africa. SCT is no longer considered a benign condition. VTE and other complications in patients with 


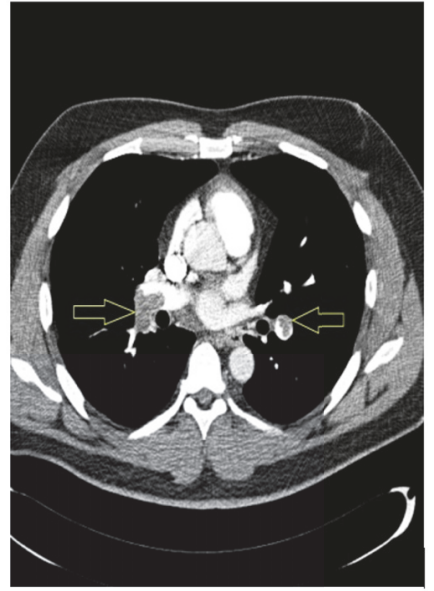

(a)

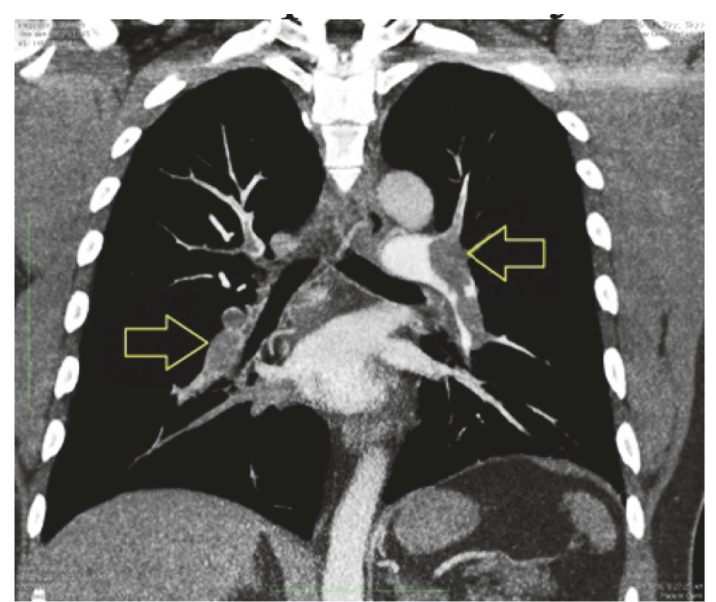

(b)

FIGURE 2: (a) CT pulmonary angiogram axial image showing a large filling defect in the right and left main pulmonary arteries affecting supply to both lobes of the lungs (see arrows). (b) CT pulmonary angiogram coronal view depicting large filling defects in the right and left main pulmonary arteries and bilateral lobar pulmonary arteries with bilateral lower lobe pulmonary atelectasis (see arrows).

SCT have been frequently reported [5-26]. Additionally, sickle cell disease and SCT have also been associated with hyperhomocysteinemia which arguably has been associated with vascular thrombosis but is not considered a strong risk factor $[10,11]$. SCT has been reported as causing venous thrombosis in many different veins in humans such as many venous beds in the legs, brain, thorax, and abdomen [12-30]. Furthermore, SCT and PE are also being linked. Massive PE has been noted previously in patients with SCT and other risk factors [28-31]. Factors contributing to such clotting tendency in HbAS patients are still unclear. Recently, the subject has been explored by studying coagulation parameters and preliminary evidence is leaning towards a prothrombotic propensity. For instance, in Nigeria, a non- "O" blood groups of individuals have been linked with thrombosis in SCT though the significance of this finding remains unknown currently $[8,32,33]$.

SCT in African Americans carries a 2-fold increased risk of PE but SCT does not elevate DVT risk according to one study [6]. Neonatal screening for sickle hemoglobin conducted in the United States of America suggests that consideration should be paid to the increased PE risk of individuals with SCT $[3-6,34]$. Whilst PE has been reported with air travel in HbSC disease, we have not found a previous report of $\mathrm{PE}$ with $\mathrm{HbAS}$ following air travel, suggesting low incidence and/or underdiagnosis $[35,36]$.

Whilst SCT may be just coincidental in our patient, there was a positive temporal relationship between a recent travel by air and $\mathrm{PE}$ in this patient with concurrence of other multiple risk factors. We hope by this report to increase awareness of a possible relationship between SCT and PE. So far, we are unable to say which individual risk factor was dominant in causing the ECS in our patient but in an individual with multiple risk factors for PE or VTE, vigorous prophylaxis would be the most pragmatic approach. Our patient has lost weight and has opted for anticoagulation for 1 year. Two years later, he regularly attends both the hematology and the medical outpatient clinic and remains without clinical, biochemical, or radiological evidence of myeloproliferative disorders, paroxysmal nocturnal hemoglobinuria, autoimmune, haematological, or mitotic diseases.

The main recommendations for travelers who are at high risk for PE or VTE are frequent ambulation, calf muscle exercise, or sitting in an aisle seat if feasible. The use of properly fitted, below knee graduated compression stockings providing $15-30 \mathrm{~mm}$ of $\mathrm{Hg}$ of pressure at the ankle and during travel is also recommended. The use of aspirin or anticoagulants as PE or VTE prophylaxis is not recommended [36]. Greater public education and research on risk factors for VTE or PE among travelers are needed.

In conclusion, although the extensive literature available on PE associated with air travel supports the existence of several individual risk factors for VTE, it appears that isolated ECS without any associated risk factor is a very rare event. Currently, the clinicians base their decisions on fitness to travel and need for prophylaxis on those risk factors for PE. However, our clinical case suggests that clinicians should start to make decisions on fitness to travel and encouragement of preventive measures based on the existence of combined risk factors in individualized cases even for short-haul flights. Also patients with SCT may be at risk for PE associated with travel when other risks for PE exist. These associations and considerations are novel and important in clinical practice and travel industry. Prophylactic measures for long-haul flights have been advocated for travel to minimize this risk but no risk scale has been described to guide physicians yet.

\section{Consent}

The patient has given written consent for publication of this manuscript. 


\section{Conflicts of Interest}

The authors declare that there are no conflicts of interest regarding the publication of this paper.

\section{Acknowledgments}

The authors thank our patient for allowing them to use his medical data for teaching purposes. The authors acknowledge the contribution made by their medical and radiology staff and the photography department.

\section{References}

[1] R. Lehmann, C. Suess, M. Leus et al., "Incidence, clinical characteristics, and long-term prognosis of travel-associated pulmonary embolism," European Heart Journal, vol. 30, no. 2, pp. 233-241, 2009.

[2] F. Lapostolle, V. Surget, S. W. Borron et al., "Severe pulmonary embolism associated with air travel," New England Journal of Medicine, vol. 345, no. 11, pp. 779-783, 2001.

[3] E. Pérez-Rodríguez, D. Jiménez, G. Díaz et al., "Incidence of air travel-related pulmonary embolism at the Madrid-Barajas airport," Archives of Internal Medicine, vol. 163, no. 22, pp. 27662770, 2003.

[4] P. S. Wells, D. R. Anderson, M. Rodger et al., "Derivation of a simple clinical model to categorize patients probability of pulmonary embolism: increasing the models utility with the SimpliRED D-dimer," Thrombosis and Haemostasis, vol. 83, no. 3, pp. 416-420, 2000.

[5] R. P. Naik and C. Haywood, "Sickle cell trait diagnosis: clinical and social implications," Hematology, vol. 2015, no. 1, pp. 160167, 2015.

[6] H. Austin, N. S. Key, J. M. Benson et al., "Sickle cell trait and the risk of venous thromboembolism among blacks," Blood, vol. 110, no. 3, pp. 908-912, 2007.

[7] A. R. Folsom, W. Tang, N. S. Roetker et al., "Prospective study of sickle cell trait and venous thromboembolism incidence," Journal of Thrombosis and Haemostasis, vol. 13, no. 1, pp. 2-9, 2015.

[8] A. S. Lawrie, A. Pizzey, S. Trompeter et al., "Procoagulant activity in patients with sickle cell trait," Blood Coagulation and Fibrinolysis, vol. 23, no. 4, pp. 268-270, 2012.

[9] T. W. Buckner and N. S. Key, "Venous thrombosis in blacks," Circulation, vol. 125, no. 6, pp. 837-839, 2012.

[10] L. A. S. Al-Maktari, M. A. K. Al-Nuzaily, S. A. Bamashmoos, S. A. G. Taresh et al., "Thrombotic events in patients with sickle cell anemia: relationship to Protein C, S and total homocysteine levels," International Journal of Current Research and Academic Review, vol. 2, no. 2, pp. 17-24, 2014.

[11] Y. I. G. V. Tichelaar and W. M. Lijfering, "Is hyperhomocysteinaemia a minor risk factor for venous thrombosis or subject to publication bias?" Netherlands Journal of Medicine, vol. 73, no. 8, pp. 394-395, 2015.

[12] J. E. Humphries and M. S. Wheby, "Case report: sickle cell trait and recurrent deep venous thrombosis," American Journal of the Medical Sciences, vol. 303, no. 2, pp. 112-114, 1992.

[13] H. C. Attal, V. L. Gupta, and H. R. Salkar, "Budd-Chiari syndrome due to inferior vena cava obstruction in sickle cell trait," The Journal of the Association of Physicians of India, vol. 32, no. 6, pp. 526-527, 1984.
[14] J. V. Rivera, "Thrombophlebitis of thoracic vein associated with sicke cell trait," Boletín de la Asociación Médica de Puerto Rico, vol. 57, pp. 306-308, 1965.

[15] T. Y. Hayashi, I. Matsuda, K. Hagiwara, T. Takayanagi, and A. Hagiwara, "Massive splenic infarction and splenic venous thrombosis observed in a patient with acute splenic syndrome of sickle cell traits on contrast-enhanced thin-slice computed tomography," Abdominal Radiology, vol. 41, no. 9, pp. 1718-1721, 2016.

[16] I. S. Boon, K. J. Starkey, O. Samsonova, and A. M. Johnston, "In the thick of it: cerebral venous sinus thrombosis precipitated by iron-deficiency anaemia and sickle cell trait," BMJ Case Reports, vol. 2016, Article ID 215399, 2016.

[17] P. Saxena, P. Dhiman, C. Bihari, and A. Rastogi, "Sickle cell trait causing splanchnic venous thrombosis," Case Reports in Hepatology, vol. 2015, Article ID 743289, 3 pages, 2015.

[18] Z. Ali, J. C. Troncoso, and D. R. Fowler, "Recurrent cerebral venous thrombosis associated with heterozygote methylenetetrahydrofolate reductase C677T mutation and sickle cell trait without homocysteinemia: an autopsy case report and review of literature," Forensic Science International, vol. 242, pp. e52-e55, 2014.

[19] L. H. Lim, R. L. Scawn, K. M. Whipple et al., "Spontaneous superior ophthalmic vein thrombosis: a rare entity with potentially devastating consequences," Eye (Basingstoke), vol. 28, no. 3, pp. 348-351, 2014

[20] W. Y. M. Abeysekera, W. D. D. De Silva, S. S. Pinnaduwa, and A. S. K. Banagala, "Acute massive splenic infarction with splenic vein thrombosis following altitude exposure of a Sri Lankan male with undetected sickle cell trait," High Altitude Medicine and Biology, vol. 13, no. 4, pp. 288-290, 2012.

[21] M. Balal, S. Paydas, and M. Inal, "Unilateral renal venous thrombosis secondary to the use of vibration belt in a young woman," Renal Failure, vol. 34, no. 9, pp. 1163-1165, 2012.

[22] F. Favale, M. Gardembas, O. Pajot et al., "Southeast Asian ovalocytosis and a sickle cell trait in a young patient with sudden retinal stroke: a fortuitous association?" Hemoglobin, vol. 33, no. 6 , pp. 475-479, 2009.

[23] M. Hedreville, P. Connes, M. Romana et al., "Central retinal vein occlusion in a sickle cell trait carrier after a cycling race," Medicine and Science in Sports and Exercise, vol. 41, no. 1, pp. 14-18, 2009.

[24] D. Cardenas and B. Ovbiagele, "Arterial dissection and cerebral venous thrombosis in sickle cell trait," British Journal of Hospital Medicine, vol. 67, no. 7, pp. 380-381, 2006.

[25] A. Wolf, M. Shalem, J. Horowitz, and O. Geyer, "Retinal vascular occlusion following traumatic hyphema and glaucoma, as a presenting sign of sickle cell trait," Israel Medical Association Journal, vol. 7, no. 7, pp. 476-477, 2005.

[26] M. M. Nachmann, J. S. Jaffe, P. C. Ginsberg, M. M. Horrow, and R. C. Harkaway, "Sickle cell episode manifesting as superficial thrombophlebitis of the penis," Journal of the American Osteopathic Association, vol. 103, no. 2, pp. 102-104, 2003.

[27] J. F. Jewett, "Sickle cell trait, thalassemia G 6 PD deficiency and puerperal pulmonary embolism," New England Journal of Medicine, vol. 295, no. 19, pp. 1076-1077, 1976.

[28] T. V. Dinh, P. J. Boor, and J. R. Garza, "Massive pulmonary embolism following delivery of a patient with sickle cell trait," American Journal of Obstetrics and Gynecology, vol. 143, no. 6, pp. 722-724, 1982.

[29] J. Sugarman, W. M. Samuelson, R. H. Wilkinson Jr., and W. F. Rosse, "Pulmonary embolism and splenic infarction in a patient 
with sickle cell trait," American Journal of Hematology, vol. 33, no. 4, pp. 279-281, 1990.

[30] E. P. Hargus, R. Shearin, and A. R. Colon, "Pulmonary embolism in a female adolescent with sickle cell trait and oral contraceptive use," American Journal of Obstetrics and Gynecology, vol. 129, no. 6, pp. 697-698, 1977.

[31] C. Amin, S. Adam, M. J. Mooberry et al., "Coagulation activation in sickle cell trait: an exploratory study," British Journal of Haematology, vol. 171, no. 4, pp. 638-646, 2015.

[32] S. G. Ahmed, M. B. Kagu, U. A. Ibrahim, and A. A. Bukar, "Impact of sickle cell trait on the thrombotic risk associated with non-O blood groups in northern Nigeria," Blood Transfusion, vol. 13, no. 4, pp. 639-643, 2015.

[33] Z. Rahimi, A. Vaisi-Raygani, R. L. Nagel, and A. Muniz, "Thrombophilic mutations among Southern Iranian patients with sickle cell disease: high prevalence of factor V Leiden," Journal of Thrombosis and Thrombolysis, vol. 25, no. 3, pp. 288292, 2008.

[34] A. B. Van Rossum, H. C. Van Houwelingen, G. J. Kieft, and P. M. T. Pattynama, "Prevalence of deep vein thrombosis in suspected and proven pulmonary embolism: a meta-analysis," British Journal of Radiology, vol. 71, pp. 1260-1265, 1998.

[35] K. Nadesan and M. Nagaratnam, "Sudden death during long distance air travel in an $\mathrm{Hb} \mathrm{S} / \mathrm{C}$ disease patient," Journal of Clinical Forensic Medicine, vol. 8, no. 3, pp. 151-155, 2001.

[36] G. H. Guyatt, E. A. Akl, M. Crowther, D. D. Gutterman, and H. J. Schuünemann, "Executive Summary: Antithrombotic Therapy and Prevention of Thrombosis, 9th ed: American College of Chest Physicians Evidence-Based Clinical Practice Guidelines," Chest, vol. 141, no. 2, supplement, pp. 7S-47S, 2012. 


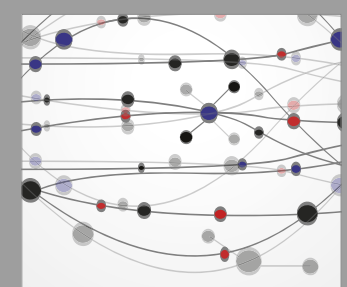

The Scientific World Journal
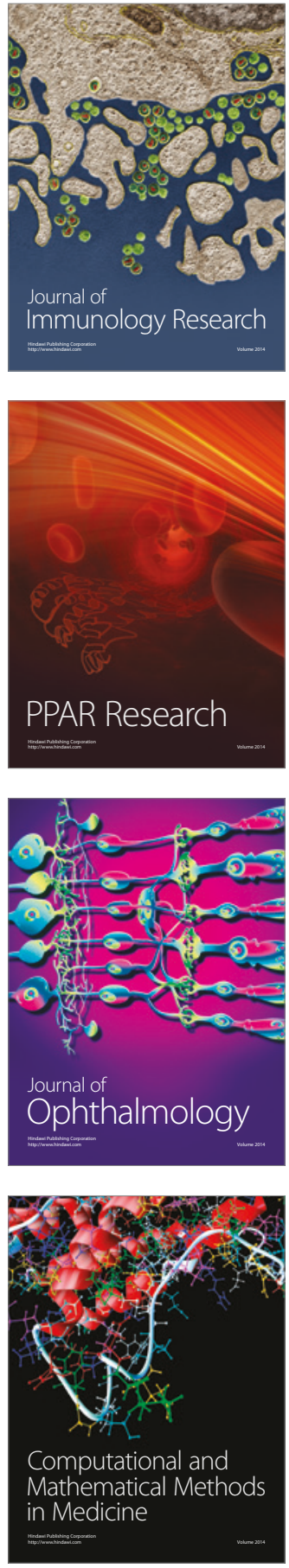

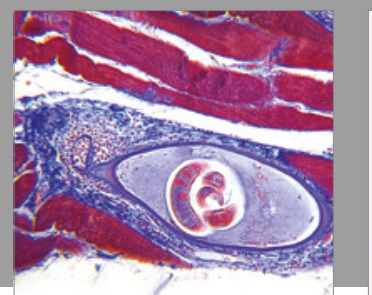

Gastroenterology Research and Practice
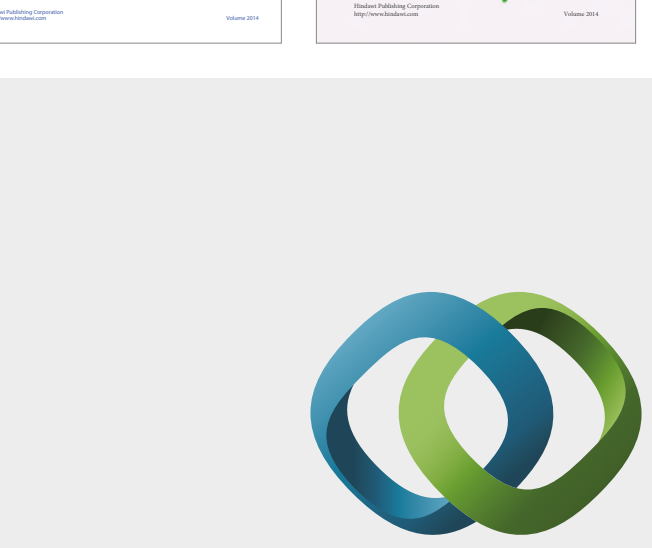

\section{Hindawi}

Submit your manuscripts at

https://www.hindawi.com
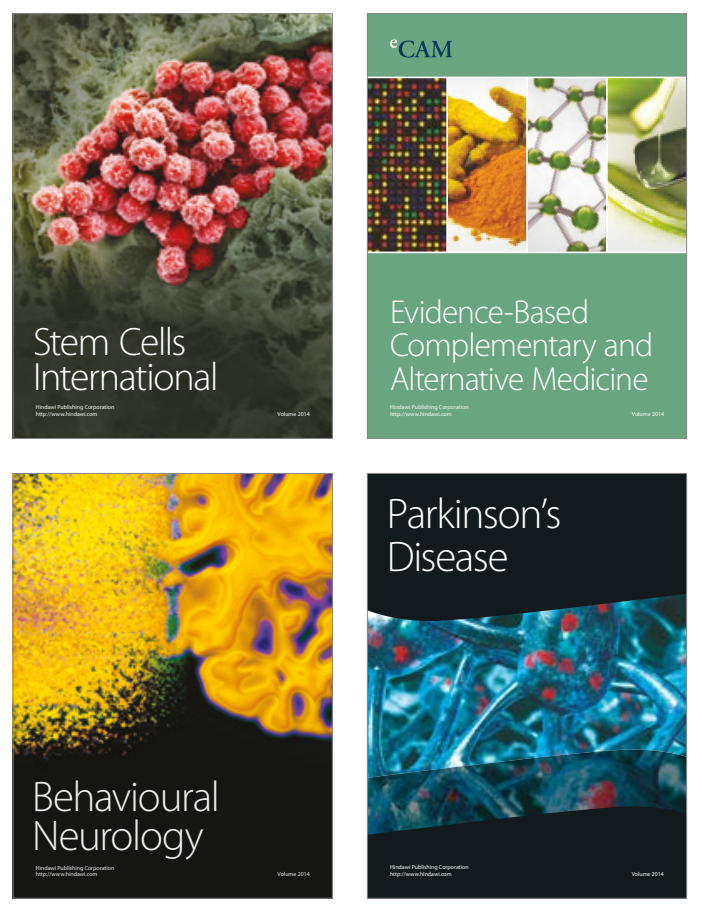
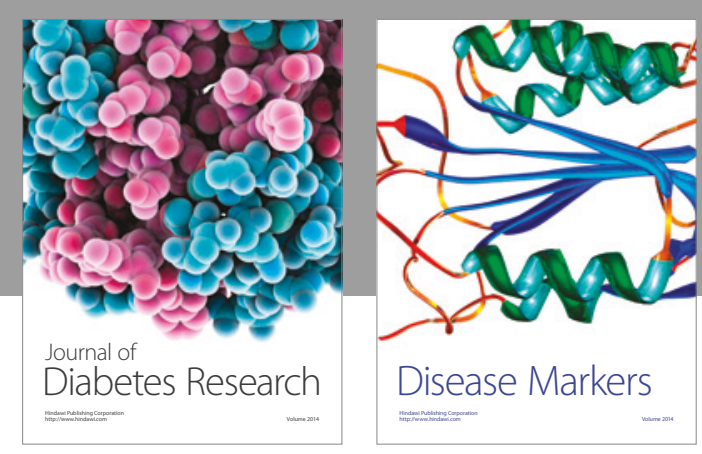

Disease Markers
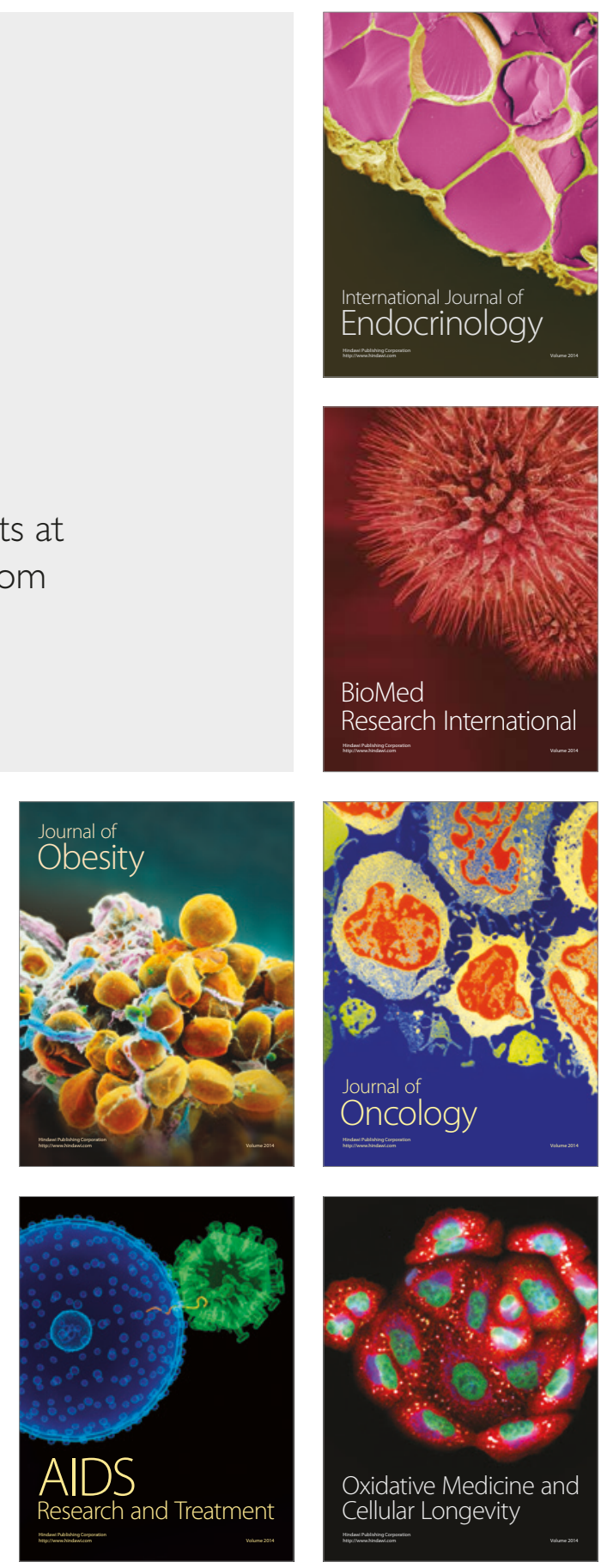